\title{
CERN PS LASER ION SOURCE DEVELOPMENT
}

\author{
P. Fournier, G. Grégoire, H. Haseroth, H. Kugler, N. Lisi, A. Lombardi, C. Meyer, P. Ostroumov, \\ W. Pirkl, J.-C. Schnuriger, R. Scrivens, V. Tenishev, F. Varela-Rodriguez (CERN, Geneva, CH) \\ S. Kondrashev, I. Roudskoy, B. Sharkov, A. Shumshurov (ITEP, Moscow, Russia) \\ S. Khomenko, K. Makarov, V. Roerich, Y. Satov, A. Stepanov (TRINITI, Troitsk, Russia)
}

\section{Abstract}

CERN, together with ITEP and TRINITI (Russia), is developing a $\mathrm{CO}_{2}$ laser ion source. The key design parameters are: $1.4 \times 10^{10}$ ions of $\mathrm{Pb}^{25+}$ in a pulse of $5.5 \mu \mathrm{s}$, with a 4-rms emittance of $0.2 \times 10^{-6} \mathrm{rad} \mathrm{m}$, working at a repetition rate of $1 \mathrm{~Hz}$. This device is considered as one candidate source for LHC heavy ion operation. The status of the laser development, the experimental set-up of the source consisting of the target area and its illumination, the plasma expansion area and extraction, beam transport and ion pre-acceleration by an RFQ, will be given.

\section{INTRODUCTION}

In 1996 a laser ion source with beam transport (LEBT) and RFQ came into operation. This system was designed for multi-charge, heavy $(\mathrm{A} \approx 200)$ ion currents $>50 \mathrm{~mA}$, charge states around 25+ [Fig. 1], [1]. The source generated $8 \mathrm{~mA}$ of $\mathrm{Ta} 20+, 28 \%$ were transported into the aperture of the RFQ. A coarsely matched beam was accelerated by the RFQ to $100 \mathrm{keV} / \mathrm{u}$. A current of 1 to $2 \mathrm{~mA}$ of Ta20+ was obtained, starting an intense effort to improve this result [2].

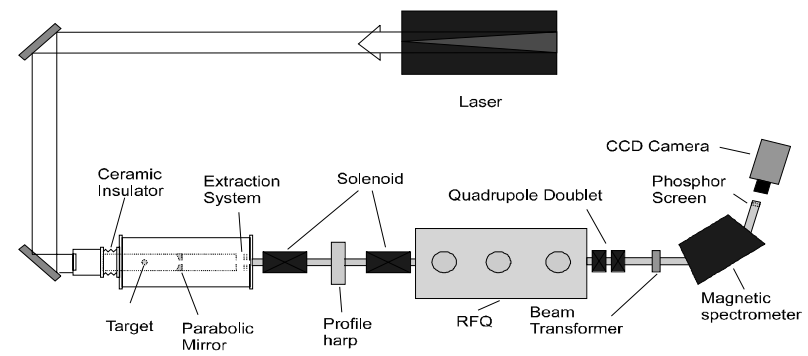

Figure 1: Scheme of the CERN Laser Ion Source

\section{WORK AT THE SOURCE}

\subsection{Matching of Plasma Density and Extraction}

The border between plasma and extracted ions together with the electric fields of the extraction electrodes and beam space-charge define the optics. Matching of the plasma and extraction is reached if the beam is smoothly focused to the LEBT. The current $(I)$ of a Faraday cup with an aperture of $30 \mathrm{~mm}$, was measured as function of extraction voltage $(U), 300 \mathrm{~mm}$ after extraction. The current density of ions in the plasma was varied by changing the target to extraction distance for laser energies of 6 and $30 \mathrm{~J}$. Figure 2 shows a measurement, $I=I(U)$, at $30 \mathrm{~J}$. Two areas can be identified, current increasing with $U$ and a flat-top, separated by a "kneevoltage", $U_{k}$. For a charge-state of $20+$ and an atomic number of 181 , the relation $U_{k}=0.45 \times 10^{6} \times I^{2 / 3}$ is found. $U_{k}$ gives the source working point.

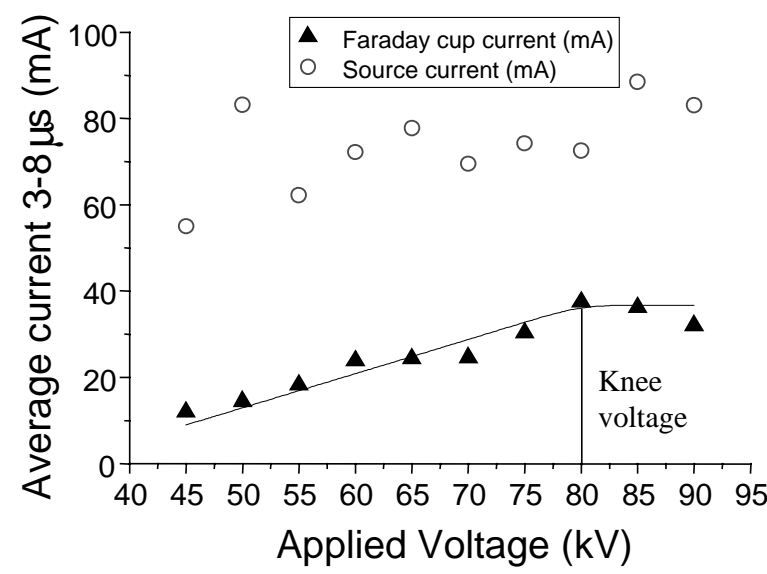

Figure 2: Characteristics of Current Transmission and Source Potential

\subsection{Emittance Measurements}

Figure 3 shows the emittance as function of extraction aperture $\phi$ at a density from 8 to $12 \mathrm{~mA} / \mathrm{cm}^{2}, \mathrm{U}=60 \mathrm{kV}$. The distance between the extraction electrodes and the apertures was kept equal. It was observed that during the beam pulse, the orientation of the phase space ellipse changes (Fig. 4) and different shaping of the source outlet electrode led to different emittances. For the present extraction geometry and a source current of 60 to $80 \mathrm{~mA}$, one finds for the ensemble of about 10 charge-states, around $\mathrm{Ta} 20+$ at $7 \mathrm{keV} / \mathrm{u}$, a total $4 \mathrm{rms}$-emittance of $300 \mathrm{mrad} \mathrm{mm}$, normalized $1.2 \times 10^{-6} \mathrm{rad} \mathrm{m}$, a value which requires improvement. At $7 \mathrm{keV} / \mathrm{u}$, measurements of the emittance using a multi-slit and phosphor screen at high currents suffer from space-charge effects. More reliable measurements of emittance can be expected at $100 \mathrm{keV} / \mathrm{u}$, after the RFQ. 


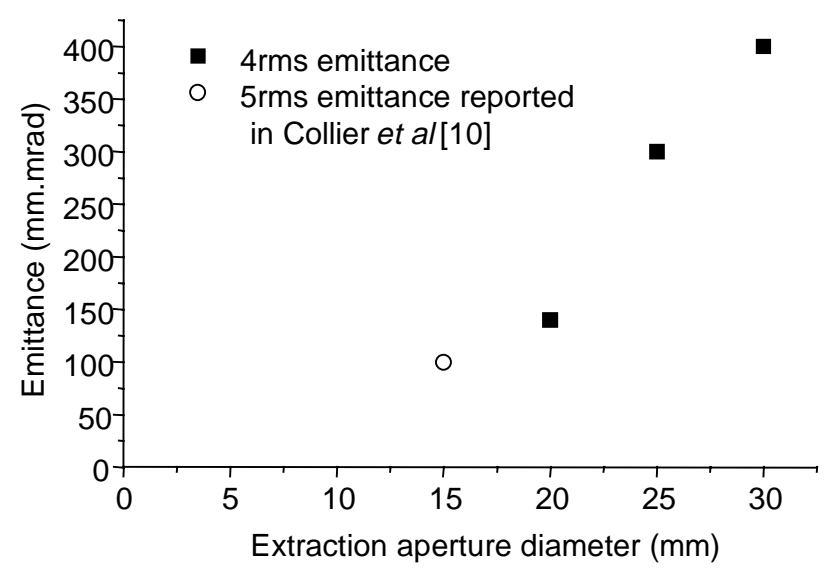

Figure 3: Emittance as a Function of Extraction Aperture

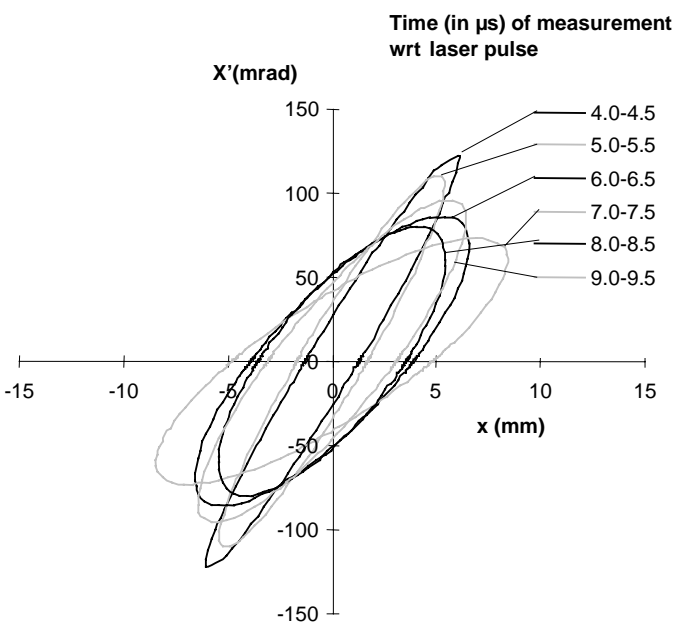

Figure 4: Emittance as a Function of Time

\begin{tabular}{|c|c|c|c|c|c|}
\hline \multicolumn{2}{|c|}{ configuration } & param. & 96 & Fall 98 [8] & Fall 98 [9] \\
\hline \multirow{2}{*}{$\phi \mathrm{FC}=\mathbf{3 0}$} & 1 sol & R30 & $33 / 58=57 \%$ & $44 / 77=57 \%$ & \\
\hline & 2 sol & R30 & $26 / 58=45 \%$ & $33 / 63=52 \%$ & \\
\hline \multirow{8}{*}{$\phi \mathrm{FC}=6.5$} & & R6.5 & & $17 / 69=25 \%$ & $17 / 63=27 \%(18)$ \\
\hline & & T6.5 & & $40 \%$ & $43 \% \quad(50)$ \\
\hline & $1 \mathrm{sol}$ & A6.5 & & $5 / 80=6 \%$ & $7 / 70=10 \% \quad(5)$ \\
\hline & & $\mathrm{Y}$ & & $11 \%$ & $16 \%(20)$ \\
\hline & & R6.5 & $10 / 60=17 \%$ & $13 / 76=17 \%(13),((11))$ & \\
\hline & & T6.5 & $28 \%$ & $28 \%(30),((40))$ & \\
\hline & 2501 & A6.5 & & $6 / 81=7 \% \quad(3), \quad((4))$ & \\
\hline & & $\mathrm{Y}$ & & $12 \%(11),((11))$ & \\
\hline \multirow{4}{*}{\multicolumn{3}{|c|}{ remarks }} & transfer from source to & good alignement & \\
\hline & & & outlet of RFQ 12\% & plasma/extraction matched & \\
\hline & & & & $d=100$ for 1 sol, $d=192$ for & $d=30$ \\
\hline & & & $E F=1.66, U=60$ & $E F=1.66, U=80$ & $E F=1.6, U=60$ \\
\hline \multirow{5}{*}{ Legend } & \multicolumn{4}{|c|}{ Rab : I ab Faraday Cup / I source [\%] } & $\mathrm{Y}:$ Yield $=\mathrm{A} 6.5^{*} \mathrm{EF}[\%]$ \\
\hline & \multirow{2}{*}{\multicolumn{4}{|c|}{ T6.5: R6.5 * EF [\%] }} & $\mathrm{U}:$ Extraction voltage $[\mathrm{kV}]$ \\
\hline & \multicolumn{2}{|c|}{ A6.5: : t through double aperture / I source [\%] } & & & $\phi \mathrm{FC}:$ Faraday Cup aperture $[\mathrm{mm}]$ \\
\hline & \multirow{2}{*}{\multicolumn{4}{|c|}{$\begin{array}{l}\text { d : image distance from solenoid [mm] } \\
\text { EF : Enhancement Factor allows for the change }\end{array}$}} & 1: Average current $[\mathrm{mA}]$ \\
\hline & & & & & ibution at transport \\
\hline
\end{tabular}

Table 1: Transfer Rates and Yields of Solenoid LEBTs

\section{WORK ON THE LEBT}

\subsection{Magnetic LEBT, Experiments and Numerical Simulations}

To improve transmission, alignment facilities for the solenoids were up-graded from $1 \mathrm{D}$ to $3 \mathrm{D}$. In some experiments the LEBT was reduced to a single solenoid line, as beam simulations [3] suggested a strong improvement of the transfer rate. The best transmission rate which could be obtained was $43 \%$. However the best particle yield was only $16 \%$, when a double aperture device was inserted at RFQ position, simulating RFQ acceptance.

The programs PATH [4], CPO [4] and KOBRA3 [4] have been used. The latter treats magnetic and electrostatic elements or fields and it allows the introduction of electrons. Simulations included the study of a LEBT with super-conducting (sc) solenoids.

\subsection{Results}

Experimental and numerical results are summarised in Table 1. Simulations for warm solenoids are given in single parenthesis and for sc solenoids in double parenthesis. None of the configurations (whether tried out in an experiment or simulated with our different programs) led to a yield (particles in the $\mathrm{xx}^{\prime} \mathrm{yy}^{\prime}$ acceptance of the RFQ) above $20 \%$. The reason is the strong non linear space charge effect from the "chained" focal points in a beam of ions of different charge states, leading to strong emittance blow-up ( $>2$, in some cases 8 times), intrinsic to all solenoids. In the beam, ring structures were observed in the transverse plane (Fig. 5).
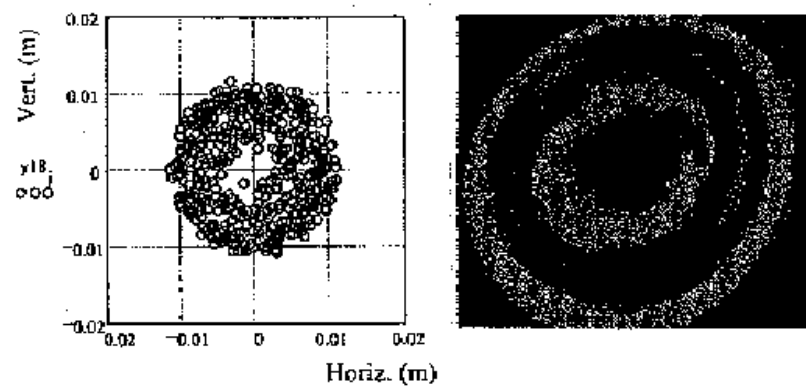

Figure 5: Ring Structures, Simulation and Experiment

\subsection{Electro-static LEBT with Grids (GEL)}

The GEL has been designed at CERN [5] and manufactured by INR, Moscow. Due to the lack of charge separation, strong non-linear space-charge effects should not appear and one expects high transfer rates compared to solenoid LEBTs. The mechanical layout of the GEL is shown in Fig. 6.

The result from beam simulations for an extracted beam of $60 \mathrm{~mA}$, and an input emittance of $320 \mathrm{mrad} \mathrm{mm}$, is shown in Fig. 7. Simulations give emittance growth $<1.5$, current transfer $>50 \%$, a yield of $35 \%$. Experiments have started recently. An average current of $40 \mathrm{~mA}$ (for solenoid LEBTs it was $17 \mathrm{~mA}$, see Table 1) has been observed in the Faraday cup of $\phi=6.5 \mathrm{~mm}$. The source current was then $70 \mathrm{~mA}$. Inserting the double aperture device gave a yield of $30 \%$. Near the focal plane, 
emittance measurements confirmed the predicted low emittance growth.

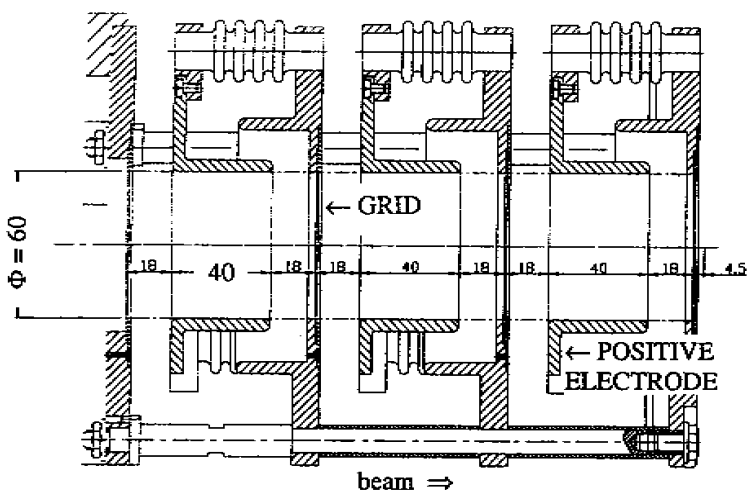

Figure 6: Mechanical Lay-out of the GEL

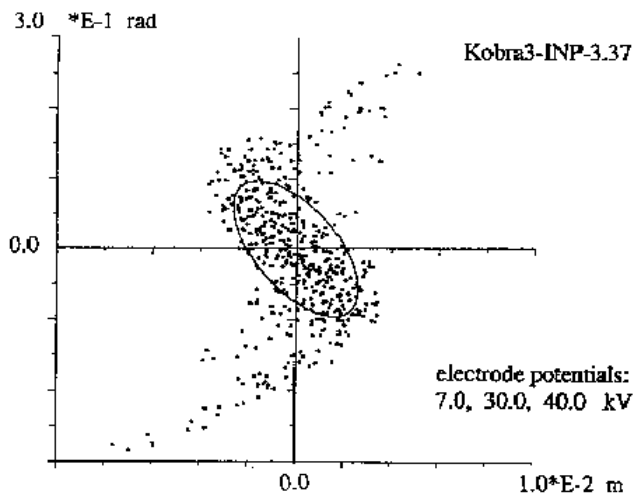

Figure 7: GEL Beam Simulations

\section{LASER DEVELOPMENTS}

\subsection{Work at TRINITI, ITEP}

In 1995, experiments with $\mathrm{CO}_{2}$ laser oscillators of $30 \mathrm{~J}$ (CERN) and 80 to $130 \mathrm{~J}$ (TRINITI) suggested that a $100 \mathrm{~J}$ laser system, consisting of a master-oscillator and poweramplifier (MO/PA) should provide more than $10^{10}$ ions of $\mathrm{Pb} 25+$ within $6 \mu \mathrm{sec}$ [6]. A master-oscillator was built by ITEP and TRINITI in 1996 and run in at CERN. It produces single transverse mode, single longitudinal mode pulses of $150 \mathrm{~mJ}$ in 60 to $70 \mathrm{~ns}$ at $3 \mathrm{~Hz}$. The realisation of a $100 \mathrm{~J}$ laser amplifier with $1 \mathrm{~Hz}$ repetition rate [7] started in December 1997. This is a joint project of ITEP and TRINITI, supported by an ISTC grant. The amplifier will be delivered to CERN by the end of 2000 . The first phase of the project included the characterisation of the ion yield to define the final laser parameters. Many configurations, 13 to $65 \mathrm{~J}$, at pulse-lengths of 15 to $80 \mathrm{~ns}$, have been run. Ion yields were measured and scaled to the $100 \mathrm{~J}$ energy level according to ion beam pulse length and current density at extraction. Extrapolating from a system, running at $13 \mathrm{~J}$ and $20 \mathrm{~ns}$ leads, with a power density of $8 \times 10^{13} \mathrm{~W} / \mathrm{cm}^{2}$ at the target, to $1.3 \times 10^{10} \mathrm{~Pb} 25+$.

\subsection{Work at CERN}

The $30 \mathrm{~J}$ laser delivers one pulse per $30 \mathrm{sec}$. To get hands-on experience with a $1 \mathrm{~Hz}$ system, a low level $1 \mathrm{~Hz}$ oscillator has been converted to an amplifier for the master-oscillator pulses. It provides $2 \mathrm{~J}$ of energy. This energy is sufficient to study LEBT performances at high currents, with light elements such as $\mathrm{Al}$.

\section{NEXT STEPS}

The RFQ will be re-installed, together with the electrostatic LEBT. Effort will be invested in the reduction of the source emittance if the results, obtained at 6 to $7 \mathrm{keV} / \mathrm{u}$, are confirmed by measurements at $100 \mathrm{keV} / \mathrm{u}$. Shaping of the extraction electrodes and modulation of extraction voltage may help. Immediate acceleration of the ions after extraction, to reduce space charge effects at transport and matching of the beam to the RFQ, is under study.

\section{REFERENCES}

[1] H. Haseroth and 21 co-authors, "Laser Ion Source Development for Heavy Ions", Proceedings of the XVIIIth International Linear Accelerator Conference, Geneva, August 1996, CERN 96-07.

[2] Thesis R. Scrivens, University of Wales, Swansea,U.K., to be published this year.

[3] B.H. Breese and J.-C. Schnuriger, "PATH Simulations of a Solenoid LEBT", PS/HP/Note 99-03 (Tech.), 1999.

[4] PATH is a program, developed at LANL, now maintained by one of the authors of this report, A. Lombardi.

CPO and KOBRA3 are commercially available programs.

[5] P. Ostroumov, "LIS LEBT on the Base of Electrostatic Gridded Lenses", PS/HP/Note 99-04 (Tech.)

[6] ILP paper, "Investigation of Highly-Charged Heavy Ion Generation”, Troitsk, August 1995.

[7] S.V. Khomenko and 4 co-authors "Master-Oscillator-Power Amplifier Laser System for Laser Ion Source", TRINITI Report 0045-A, August 1998.

[8] N. Lisi and 3 co-authors, "Experimental Characterisation of Solenoid LEBT for LIS Source", PS/HP/Note 98-14 (Tech.), 1998.

[9] P. Fournier and 4 co-authors, "Experimental Characterisation of Solenoid LEBT for LIS Source: Short Solenoid to Extraction Distance", PS/HP/Note 99-02 (Tech.), 1999.

[10] J. Collier and 4 co-authors, "Emittance Measurements on the CERN Laser Ion Source”, PS/HI/Note 95-07 (Tech.), 1995. 